This item was submitted to Loughborough's Institutional Repository (https://dspace.lboro.ac.uk/) by the author and is made available under the following Creative Commons Licence conditions.

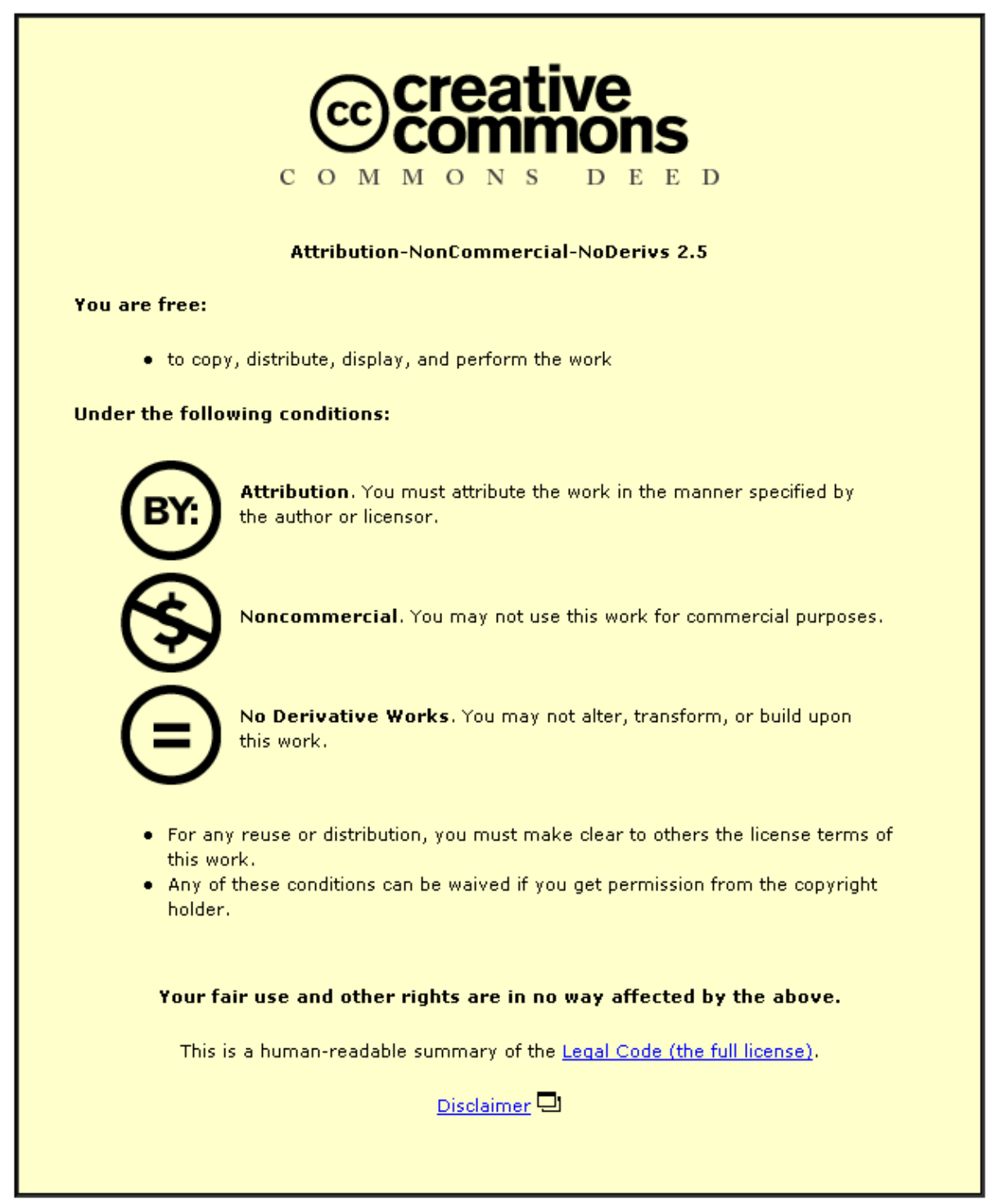

For the full text of this licence, please go to: http://creativecommons.org/licenses/by-nc-nd/2.5/ 


\title{
Postbuckled Stability of Panels with Torsional Buckling
}

\author{
A. Watson ${ }^{1}$ and P.E. Fenner ${ }^{2}$ \\ Loughborough University, Loughborough LE11 3TU, UK \\ and \\ C.A. Featherston ${ }^{3}$ and D. Kennedy ${ }^{4}$, \\ Cardiff University, Queen's Buildings, The Parade, Cardiff CF24 3AA, UK
}

\begin{abstract}
The panel analysis and optimization code VICONOPT, based on exact strip theory, is utilized to investigate the postbuckling stability of a stiffened aerospace panel in a torsional buckled state. The paper shows that the postbuckling characteristics of a panel buckling in a torsional mode has similarity to the postbuckling behavior of a panel with a skin initiated mode and a panel initiated mode. The postbuckled stiffness of the torsional mode is similar to the skin mode in terms of load versus end shortening and is similar to the panel postbuckling behavior in terms of load versus out-of-plane deflection. If the panel has stiffeners of more than one size then there are multiple torsional modes. For panel design it is suggested that small stiffener buckling, i.e., in a torsional mode, can have postbuckling stability with regard to the growth of the out-of-plane deflection. If the large stiffeners initiate the buckling then there is no postbuckling reserve of strength. This has implications for design of such panels as mass could be saved if allowance is made for small stiffener buckling in the optimization process.
\end{abstract}

\section{Introduction}

C TIFFENED panels in aerospace applications can have a considerable postbuckling reserve of strength, enabling them to remain in stable equilibrium under loads in excess of their critical buckling load, provided the initial buckling mode is a local one ${ }^{1}$. This paper shows that in addition to this postbuckling strength stiffened panels also have a limited postbuckling reserve strength if the panel has an initial buckling mode initiated by torsional buckling of the stiffeners, provided that the stiffened panel has (at least) two sizes of stiffener. Stiffened panels with multiple stiffener sizes give rise to a range of possible torsional modes. Modes can be grouped into categories with the number of different categories of mode equal to the number of different stiffener types.

A previous investigation by Williams ${ }^{2}$, into the optimization of stiffened panels with multiple stiffener sizes, using a predecessor of the computer code VICONOPT ${ }^{3}$, made no allowance for the postbuckling reserve of strength and the local and overall buckling stresses for the optimum designed panel were coincident. Williams ${ }^{2}$ was able to determine the panel characteristics that affected the buckling stresses for local and overall buckling modes but not the intermediate modes. Anderson ${ }^{4}$ later extended the capability of VICONOPT to allow for postbuckling reserve of strength in optimum design. In a recent paper by Watson et $\mathrm{al}^{5}$ the buckling stability of optimum panels with more than one stiffener size was investigated. In that investigation the critical buckling mode was local buckling of the skin portions between the stiffeners. A typical optimum postbuckled stiffened panel should result in the critical buckling stress occurring with a skin mode and a higher buckling stress for the overall mode. At any bifurcation point there will be a redistribution of stresses and a growth in out-of-plane deflection resulting in a reduction in the stiffness of the whole section. When local buckling occurs the overall buckling stress will reduce further, hence it is important that there is a significant difference in the initial and overall buckling loads for the panel to ensure postbuckling stability ${ }^{6}$. If there is more than one stiffener size and the smaller stiffeners initiate the bifurcation behavior with a torsional mode, then the stiffeners have to be sized such that the panel is stable after this stress

\footnotetext{
${ }^{1}$ Lecturer, Department of Aeronautical and Automotive Engineering, Member AIAA.

${ }^{2} \mathrm{PhD}$ Student, Department of Aeronautical and Automotive Engineering.

${ }^{3}$ Senior Lecturer, Cardiff School of Engineering.

${ }^{4}$ Reader, Cardiff School of Engineering, Senior Member AIAA.
} 
redistribution. There is very little work in the literature on the postbuckling stability of torsional modes and so an investigation into the buckling and postbuckling stability of panels with critical torsional modes is warranted. In their recent paper Bushnell and Rankin ${ }^{7}$ reported on the enhancement of the computer program PANDA2 ${ }^{8}$ to permit the optimization of flat and/or cylindrical panels and shells with substiffeners. The authors then used the code to find the minimum weight designs of cylindrical shells with T-shaped stringers and rectangular substringers but the optimization did not allow for post local buckling behavior for panels with substiffeners.

Typically investigation of the postbuckled stability of a stiffened panel with a torsional mode requires that the critical buckling load of the panel is associated with a torsional mode. This is a limitation of finite element programs such as NASTRAN ${ }^{9}$ and ABAQUS ${ }^{10}$. The exact strip program VICONOPT (see below) does not have this restriction, as the user can select the buckling half-wavelength and hence investigate any postbuckling behavior regardless of the criticality of the mode.

In this investigation three programs are used. VICONOPT is used for both initial buckling and postbuckling analysis of all panels looked at; NASTRAN is used to determine the initial buckling of a blade stiffened panel; and ABAQUS is used to determine its postbuckling behavior. Two panels are analyzed: one is a blade stiffened panel, and one is a panel with two stiffener sizes. No optimization is performed in this paper.

\section{Theoretical Background to VICONOPT}

VICONOPT (VIPASA with CONstraints and OPTimization) is a FORTRAN 77 computer program that incorporates the earlier programs VIPASA (Vibration and Instability of Plate Assemblies including Shear and Anisotropy) and VICON (VIPASA with CONstraints). It covers any prismatic plate assembly, i.e., a panel of constant cross section, composed of anisotropic plates each of which can carry any combination of uniformly distributed and longitudinally invariant in-plane stresses. It can be used as either an analysis or an optimum design program. The analysis principally covers the calculation of eigenvalues, i.e., the critical load factors in elastic buckling problems or the natural frequencies in undamped vibration problems, and uses an exact stiffness approach resulting from solution of the governing differential equations of the constituent members. In the simplest form of analysis $^{11}$, deformation is assumed to vary sinusoidally to infinity in the longitudinal direction, yielding exact stiffness matrices whose elements are transcendental functions of the load factor or frequency and the axial halfwavelength, $\lambda$, of the deformation. The resulting transcendental eigenproblem requires an iterative solution which is performed using the Wittrick-Williams algorithm ${ }^{12}$. Analyses are performed over a range of values of $\lambda$ that usually extends from a value less than the smallest plate width to the length, $l$, of the panel. The lowest buckling load found for any $\lambda$ is taken as the critical buckling load for the panel. This implies that the panel of length $l$ is simply supported at its ends with warping of the entire cross-section allowed.

The VIPASA ${ }^{11}$ analysis option of VICONOPT has been extended to cover local postbuckling of longitudinally compressed panels ${ }^{13}$. Each component plate is divided into longitudinal strips of equal width. The longitudinal stress resultant takes a peak value at the supported edges where there is no out-of-plane deflection, and elsewhere is reduced due to the out-of-plane flexure of its line of action; uniform values are assumed across each strip. The analysis comprises a number of cycles, each defined by a pre-determined increment of longitudinal and/or shear strain. Within each cycle, it is necessary to determine the total applied loads, the variation of stress resultants across the structure, and the amplitude and shape of the postbuckling mode. The key feature of the method is accurate convergence on the mode using Newton iterations, which in turn enables calculation of the postbuckling stress distribution and total loads on the structure.

\section{Stability of Blade Stiffened Panel}

\section{A. Initial Buckling Behavior}

Figure 1 shows the cross section of a six blade stiffened panel from Ref 14. The panel is square in plan with length $l=762 \mathrm{~mm}$. The skin thickness $t$ is $1.27 \mathrm{~mm}$ and the stiffener thickness $T$ is $1.473 \mathrm{~mm}$. Stiffener pitch $b$ is $127 \mathrm{~mm}$ and the skin breadth from stiffener to support is $63.5 \mathrm{~mm}$. The panel is metal with Young's modulus $E=$ $72.4 \mathrm{GNm}^{-2}$ and Poisson's ratio $v=0.32$. The longitudinal edges are simply supported and the ends are diaphragm supported. The loading is pure compressive.

The initial buckling load is $39.47 \mathrm{kN}$ and the corresponding strain is $430 \mu \varepsilon$. The critical mode is a local skin initiated mode with $\lambda=l / 6$ and the eigennumber is 1 . The results of the full buckling analysis are compared with results obtained using NASTRAN in Table 1. The mode shapes are shown in Fig. 2. The load associated with an overall buckling mode is 2.875 times the initial buckling load which has an associated local mode. This 
characteristic demonstrates this particular panel's stable postbuckling behavior. The load associated with the torsional mode is 2.493 times the initial buckling load. There is no postbuckling stability with this mode shape (see below) but again the associated critical load for this mode occurs well above that of the local mode. The NASTRAN comparison demonstrates the suitability of both codes to conduct buckling analysis. However to obtain the higher eigenvalues indicated in Table 1 required the calculation of all eigenvalues starting from the lowest and checking each eigenmode in turn. This limits the ability of finite element programs such as NASTRAN and ABAQUS to conduct initial non-critical buckling analysis. VICONOPT does not have this restriction because the user can select the buckling half-wavelength directly. In addition solution times are reduced by two orders of magnitude.

The NASTRAN solutions were obtained by modeling simply supported boundary conditions on the loaded edge with the use of rigid body elements (type RBE2 - Ref 9) to ensure that only rotation occurred on the loaded edge and no out-of-plane displacement. Poisson's effect was allowed for in the constraints. These boundary conditions therefore show a better quality comparison for the higher buckling loads with VICONOPT which assumes simply supported ends. For the local buckling result the boundary conditions have negligible effect.

Table 1. Comparison of the critical buckling loads for all modes of blade stiffened panel using both VICONOPT and NASTRAN for the analysis.

\begin{tabular}{cccccc}
\hline \hline & & VICONOPT & \multicolumn{2}{c}{ NASTRAN } \\
Mode & Half-wavelength & Critical Load kN & Eigennumber & Critical Load kN & Eigennumber \\
\hline Local & $\lambda=l / 6$ & 39.47 & 1 & 39.36 & 1 \\
Torsional & $\lambda=l / 2$ & 98.41 & 76 & 99.55 & 73 \\
Overall & $\lambda=l$ & 113.5 & 85 & 113.4 & 84 \\
\hline \hline
\end{tabular}

\begin{tabular}{c|l|l|l|l|l|l}
\multicolumn{2}{c}{2} & \multicolumn{2}{c}{3} & 4 & 5 & 6 \\
$\Delta$ & 8 & 9 & 10 & 11 & 12 & 13
\end{tabular}

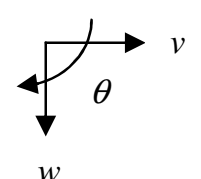

Figure 1. Cross section of six-blade square panel ${ }^{\mathbf{1 4}}$. The numbers refer to plates for which mode and postbuckling data is obtained in Tables 1 and 2.

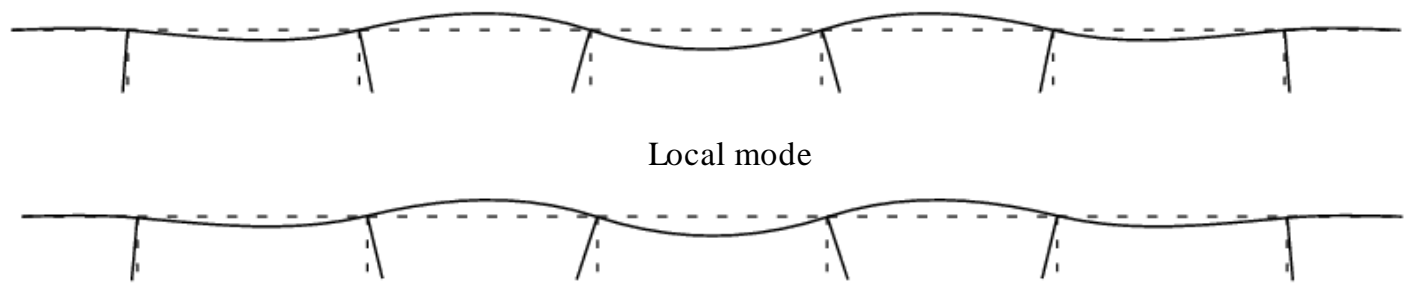

Torsional mode

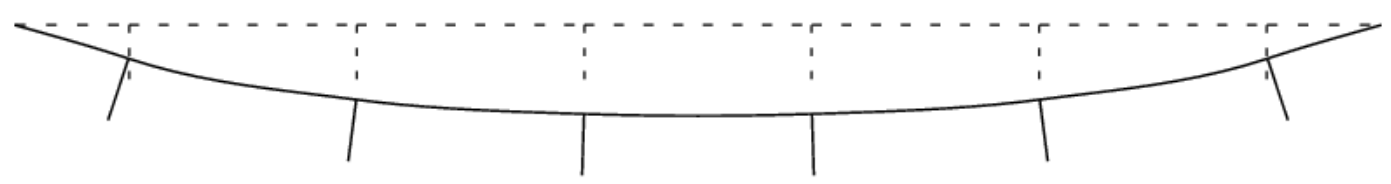

Overall mode

Figure 2. The computed buckling modes for stiffened panel of Fig. 1. The unperturbed panel is shown dashed. 
The distinguishing features for each mode can be seen in Fig. 2. Typically for overall modes the longitudinal line junctions between the stiffener webs and the skin displace and therefore are not straight, and in practice there is one half wave across the width which looks similar to a half sine wave. In the torsional and local modes the web/skin line junctions do not displace to first order accuracy and therefore remain straight. Because the blades of the stiffened panel have no flanges the torsional and local modes appear very similar.

However there are very important differences that can only be seen by examining the numerical values of the buckling mode displacements. All the significant displacements of each mode are shown in Table 2. The maximum value for each displacement is shown bold and occurs either in the middle or at the end of a plate. The first column defines the nodal location where three numbers refer to the node at the junction of the three numbered plates; $\mathrm{S}$ refers to the node where a plate meets a longitudinal support; $\mathrm{T}$ refers to tip or free end of plate; and $\mathrm{M}$ refers to middle of plate. The displacements of each mode are normalized with respect to the maximum rotation. The longitudinal displacements are ignored because they are small. For the local buckling mode initiated by skin buckling the maximum out-of-plane displacement occurs in plate 4 . The maximum rotation occurs in the two webblade junctions at each end of plate 4 . The numerical data shows no out-of-plane displacement at all the blade-skin junctions. For the torsional mode the largest rotation occurs at the blade tips for the two innermost blades. Note that the largest out-of-plane displacement is still in plate 4 but this is less than in the local mode and the tip deflection is greater for the torsional mode. As in the local mode, there is no out-of-plane displacement at the blade-skin junctions. The overall mode shows the largest rotation occurs at the tips of the outermost blades with maximum lateral displacement occurring in the middle plate.

Table 2. Displacements of nodes at initial buckling for each buckling mode type.

\begin{tabular}{cccccccccc}
\hline \hline \multirow{2}{*}{ Node location } & \multicolumn{3}{c}{ Local Mode } & \multicolumn{4}{c}{ Torsional Mode } & \multicolumn{3}{c}{ Overall Mode } \\
& $v$ & $w$ & $\theta$ & $V$ & $w$ & $\theta$ & $v$ & $w$ & $\theta$ \\
\hline $1, \mathrm{~S}$ & 0.000 & 0.000 & -0.118 & 0.000 & 0.000 & 0.085 & -0.001 & 0.000 & 0.846 \\
$1,2,8$ & 0.000 & 0.000 & 0.268 & 0.000 & -0.002 & -0.265 & -0.001 & 0.056 & 0.992 \\
$2 \mathrm{M}$ & 0.000 & 0.024 & 0.103 & 0.000 & -0.021 & -0.074 & -0.001 & 0.110 & 0.474 \\
$2,3,9$ & 0.000 & 0.000 & -0.732 & 0.000 & 0.001 & 0.720 & -0.001 & 0.125 & 0.389 \\
$3 \mathrm{M}$ & 0.000 & -0.042 & -0.059 & 0.000 & 0.036 & 0.043 & 0.000 & 0.155 & 0.164 \\
$3,4,10$ & 0.000 & 0.000 & $\mathbf{1 . 0 0 0}$ & 0.000 & 0.000 & -0.980 & 0.000 & 0.149 & 0.098 \\
$4 \mathrm{M}$ & 0.000 & $\mathbf{0 . 0 4 8}$ & 0.000 & 0.000 & $\mathbf{- 0 . 0 4 1}$ & 0.000 & 0.000 & $\mathbf{0 . 1 6 7}$ & 0.000 \\
$4,5,11$ & 0.000 & 0.000 & $\mathbf{- 1 . 0 0 0}$ & 0.000 & 0.000 & 0.980 & 0.000 & 0.149 & -0.098 \\
$5 \mathrm{M}$ & 0.000 & -0.042 & 0.059 & 0.000 & 0.036 & -0.043 & 0.000 & 0.155 & -0.164 \\
$5,6,12$ & 0.000 & 0.000 & 0.732 & 0.000 & 0.001 & -0.720 & 0.001 & 0.125 & -0.389 \\
$6 \mathrm{M}$ & 0.000 & 0.024 & -0.103 & 0.000 & -0.021 & 0.074 & 0.001 & 0.110 & -0.474 \\
$6,7,13$ & 0.000 & 0.000 & -0.268 & 0.000 & -0.002 & 0.265 & 0.001 & 0.056 & -0.992 \\
$7, \mathrm{~S}$ & 0.000 & 0.000 & 0.118 & 0.000 & 0.000 & -0.085 & 0.001 & 0.000 & -0.846 \\
$8 \mathrm{~T}$ & -0.008 & 0.000 & 0.224 & 0.009 & -0.002 & -0.270 & -0.035 & 0.056 & $\mathbf{1 . 0 0 0}$ \\
$9 \mathrm{~T}$ & 0.022 & 0.000 & -0.611 & -0.025 & 0.001 & 0.735 & $\mathbf{- 0 . 0 1 4}$ & 0.124 & 0.393 \\
$10 \mathrm{~T}$ & $\mathbf{- 0 . 0 3 0}$ & 0.000 & 0.835 & $\mathbf{0 . 0 3 4}$ & 0.000 & $\mathbf{- 1 . 0 0 0}$ & -0.004 & 0.148 & 0.099 \\
$11 \mathrm{~T}$ & $\mathbf{0 . 0 3 0}$ & 0.000 & -0.835 & $\mathbf{- 0 . 0 3 4}$ & 0.000 & $\mathbf{1 . 0 0 0}$ & 0.004 & 0.148 & -0.099 \\
$12 \mathrm{~T}$ & -0.022 & 0.000 & 0.611 & 0.025 & 0.001 & -0.735 & $\mathbf{0 . 0 1 4}$ & 0.124 & -0.393 \\
$13 \mathrm{~T}$ & 0.008 & 0.000 & -0.224 & -0.009 & -0.002 & 0.270 & 0.035 & 0.056 & $\mathbf{- 1 . 0 0 0}$ \\
\hline \hline
\end{tabular}

\section{B. Postbuckling Behavior}

The normalized load versus normalized end shortening plot for the postbuckling behavior, obtained using VICONOPT, for the blade stiffened panel is shown in Fig. 3a. The figure shows the postbuckling behavior for all three modes and also includes the local postbuckling behavior obtained using ABAQUS. Note that each plot has

4

American Institute of Aeronautics and Astronautics 
been normalized with respect to the critical load and end shortening strain for its respective mode, hence all the plots pass through $(0,0)$ and $(1,1)$. The analysis of the behavior of the two local modes for both ABAQUS and VICONOPT shows reasonable agreement. VICONOPT gives a smaller postbuckling stiffness because the longitudinal edges have been allowed to move in-plane; other edge conditions have previously been modeled using an empirical transverse tension factor ${ }^{15}$. The VICONOPT overall and torsional mode results are almost identical. The curve for the overall mode becomes progressively flatter as load is increased. Figure $3 \mathrm{~b}$ shows load versus outof-plane deflection plots for these modes. For ABAQUS the postbuckling analysis was performed by mapping the initial eigenmode as an initial imperfection hence this curve does not pass through $(0,1)$. The ABAQUS plot shows postbuckling stability for the panel shown by the positive gradient of this curve. The VICONOPT result for the local mode shows a similar behavior noting that the increase of load versus displacement is much slower. The torsional and overall modes show a flat curve demonstrating essentially zero postbuckling stability, i.e., although the load can be increased above the buckling load, this would entail excessively large out-of-plane displacements.

The postbuckling stiffness of the component plates is shown in Table 3 for the three modes of buckling halfwavelength $l / 6, l / 2$ and $l$ (i.e., the local, torsional, and overall modes, respectively). The stiffness values represent the inplane stiffness relative to its prebuckling value, and are measured at the start of postbuckling behavior - i.e., the gradient of the load versus end shortening curve in Fig. 3a. Generally the postbuckled stiffness of the component plates will always be less than unity as there is a loss of stiffness at buckling. Plates with postbuckling stiffness have the ability to carry additional load, but the out-of-plane deflection as seen in Fig. $3 \mathrm{~b}$ can grow very quickly for certain modes. The results for the local mode show a reduced stiffness for component plate number 4 which initiates buckling. The outer portions of skin have lost less stiffness due to their smaller out-of-plane displacements. The blades have high values of post local buckling stiffness, again due to the reduced out-of-plane displacements, noting that the innermost blades have the lowest stiffness. For torsional mode postbuckling there is a considerable loss of stiffness in the central skin plate 4. This is due to the large out-of-plane deflections at the tips of plates 10 and 11. The resulting rotation caused by these tip deflections at the junctions $3,4,10$ and 4,5,11 has a causal effect on the central deflection in plate 4 . This is not buckling precipitated by plate 4 , but torsional buckling of the blades 10 and 11 resulting in the large displacement and loss of stiffness in plate 4. The stiffness of blades 10 and 11 shows a big reduction when compared with the local mode postbuckling stiffness values. The mode associated with $\lambda=l / 2$ is thus shown to be a torsional mode of the blade and not local buckling of the skin, verified by checking the relative displacements at buckling. For the overall mode the large flexural displacements in the central skin portions cause the stiffnesses to become negative in plates 3,4, and 5, and also in blades 10 and 11 .

Table 3. Initial Postbuckled Stiffness of Stiffened Panel Plates

\begin{tabular}{|c|c|c|c|c|}
\hline & Plate number & $\begin{array}{l}\text { Local } \\
\lambda=l / 6\end{array}$ & $\begin{array}{c}\text { Torsional } \\
\lambda=l / 2\end{array}$ & $\begin{array}{c}\text { Overall } \\
\lambda=l\end{array}$ \\
\hline \multirow{7}{*}{$\begin{array}{l}\text { Skin } \\
\text { Plates }\end{array}$} & 1 & 0.9967 & 0.9983 & 0.9493 \\
\hline & 2 & 0.7979 & 0.7576 & 0.4572 \\
\hline & 3 & 0.4025 & 0.2859 & -0.0955 \\
\hline & 4 & 0.2060 & 0.0554 & -0.2713 \\
\hline & 5 & 0.4024 & 0.2859 & -0.0955 \\
\hline & 6 & 0.7978 & 0.7576 & 0.4572 \\
\hline & 7 & 0.9967 & 0.9983 & 0.9493 \\
\hline \multirow{6}{*}{$\begin{array}{l}\text { Stiffener } \\
\text { Webs }\end{array}$} & 8 & 0.9843 & 0.9633 & 0.8203 \\
\hline & 9 & 0.8830 & 0.7573 & 0.2147 \\
\hline & 10 & 0.7824 & 0.5553 & -0.1111 \\
\hline & 11 & 0.7824 & 0.5553 & -0.1111 \\
\hline & 12 & 0.8830 & 0.7573 & 0.2147 \\
\hline & 13 & 0.9843 & 0.9633 & 0.8203 \\
\hline
\end{tabular}



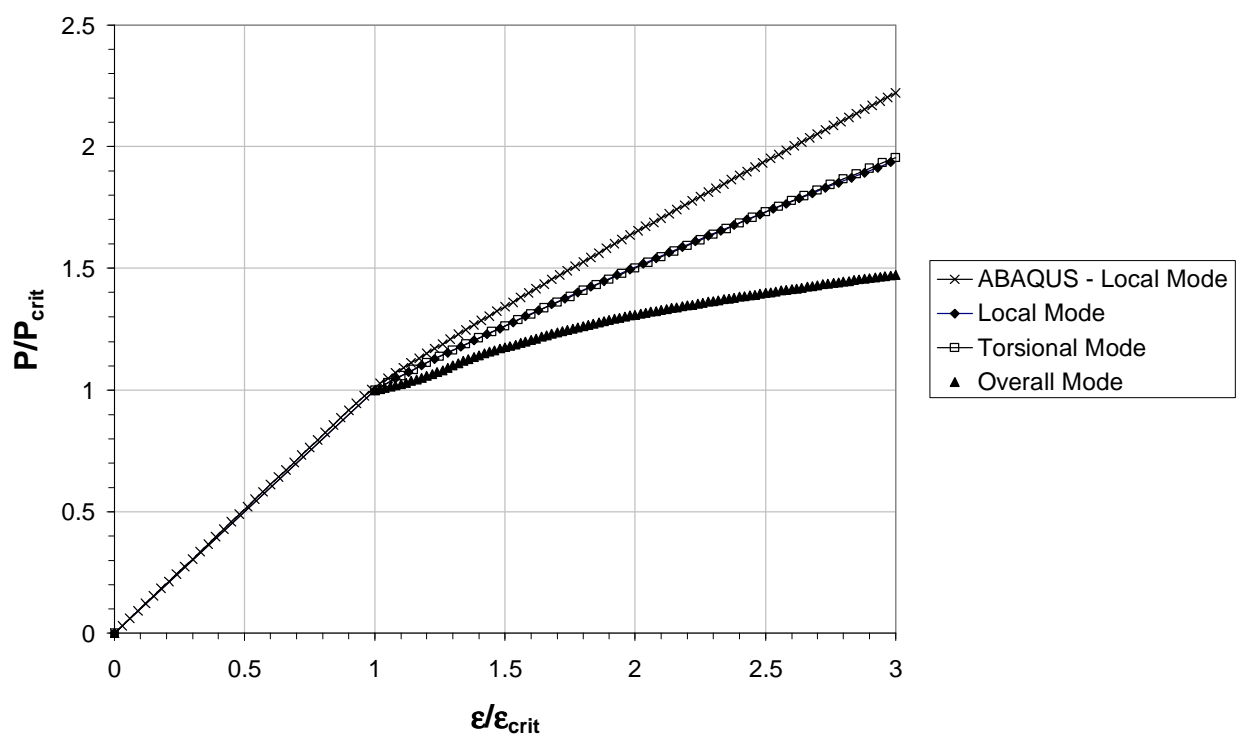

(a)

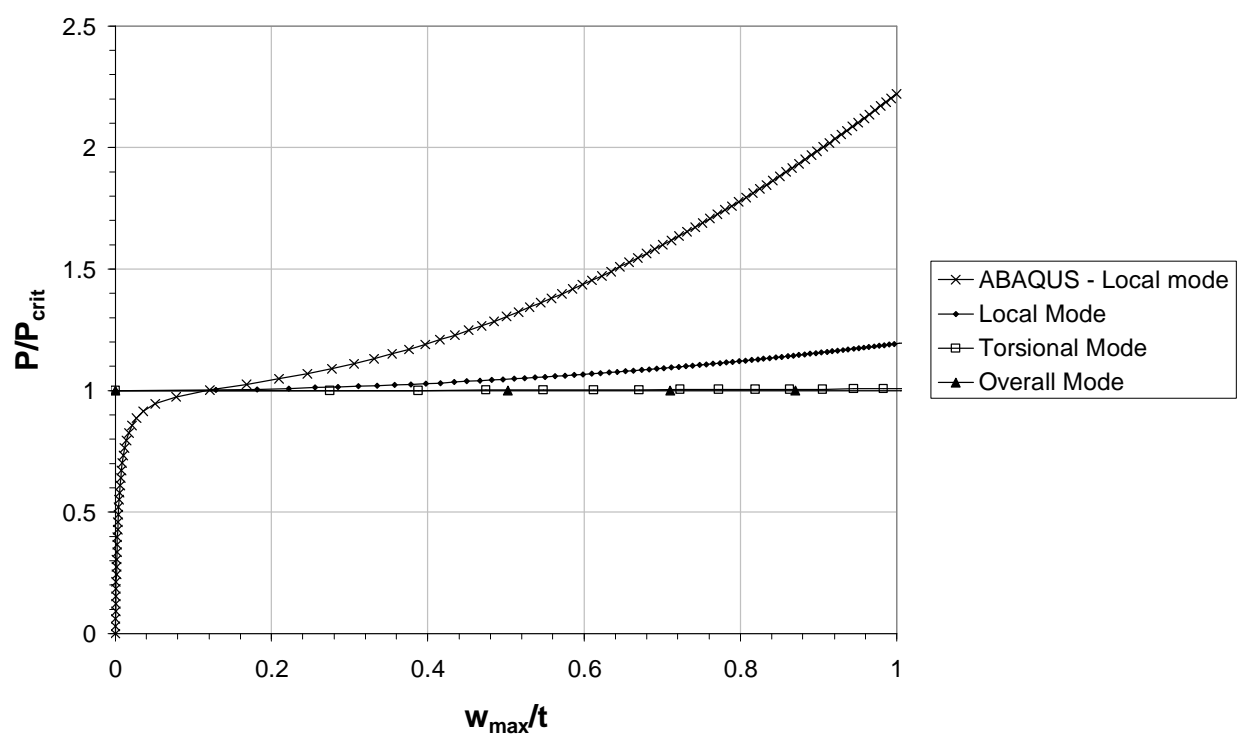

(b)

Figure 3. (a) Load versus end shortening. (b) Load versus out-of-plane deflection

\section{Stability of Stiffened Panels with Multiple Stiffener Sizes}

\section{A. Initial Buckling Behavior}

The panels optimized by Williams ${ }^{2}$ had coincident local and overall buckling stresses. This stemmed from the design procedure which was a compromise between local and overall buckling requirements. The requirements for local buckling were twofold: firstly there must be enough stiffeners to prevent buckling of the skin between stiffeners; and secondly all component plates of the stiffeners must be adequately thick. The overall buckling requirements were an adequate second moment of area, which is most easily achieved when only a few stiffeners are used; and the stiffeners should be very thin. It is seen that the local buckling constraints conflict with the overall buckling constraints, leading to a panel design with coincident local and overall buckling stresses. Such panels have 
no postbuckling reserve of strength, and may fail at a stress below the local or overall buckling stress due to imperfections. The buckling modes of the stiffened panels optimized fell into the three categories of local, torsional and overall modes with the torsional buckling loads higher than the local and overall loads. The number of torsional modes depends on the number of different stiffener sizes. Williams speculates about possible panel configurations to save mass, although no allowance is made for postbuckling behavior.

Figure 4 shows the cross section of an isotropic, rectangular panel with two different sizes of stiffener, which is loaded in longitudinal compression. Figure 5 shows the relationship between the critical buckling stress and longitudinal half-wavelength $\lambda$ for the panel of Fig. 4. The buckling stresses were obtained by using the VIPASA [11] option in VICONOPT. The buckling modes fall into the four categories, labeled Modes A, B, C and D. These four modes are identified as local, torsional $(\times 2)$ and overall as seen in Fig. 6 which shows the characteristics of each of four mode shapes for the lowest eigenvalues only.

The distinguishing features of the local mode (Mode A) and overall mode (Mode D) are similar to those of the blade stiffened panel of Fig. 1. For the local mode all line junctions between two orthogonal plates remain straight. Because all the stiffeners have flanges, the tips of the webs remote from the skin do not displace. In this mode the tips of the flanges remote from the web do displace since they are free edges, as can be seen in Fig. 6.

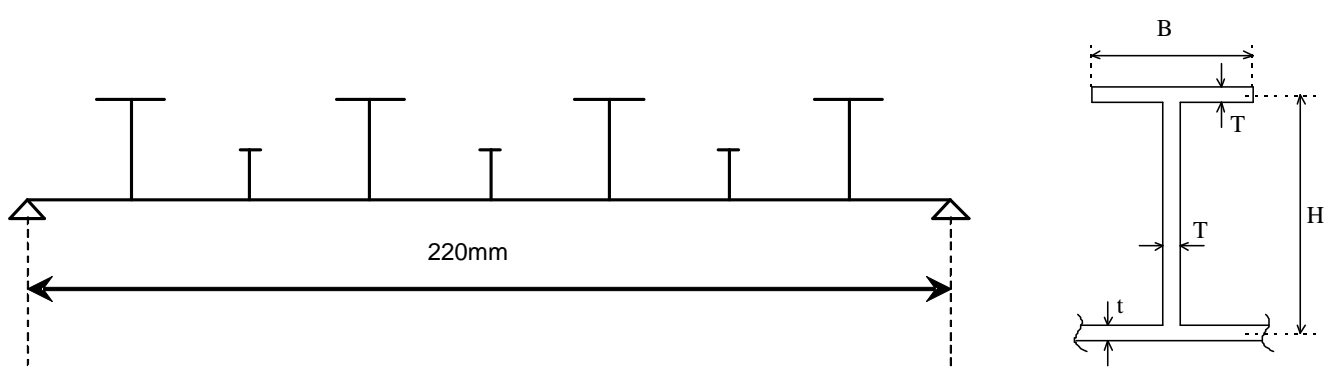

Figure 4. Cross section of prismatic stiffened panel. The stiffener pitch $(b)$ is $30 \mathrm{~mm}$. The two outstands are $20 \mathrm{~mm}$ in breadth. The inter stiffener skin portions have $b / t=30$, and the large stiffeners have $T=t, H=b$, and $B=2 b / 3$, while $T=0.6 t, H=b / 2$, and $B=b / 5$ for the small stiffeners. The panel is simply supported on all four edges.

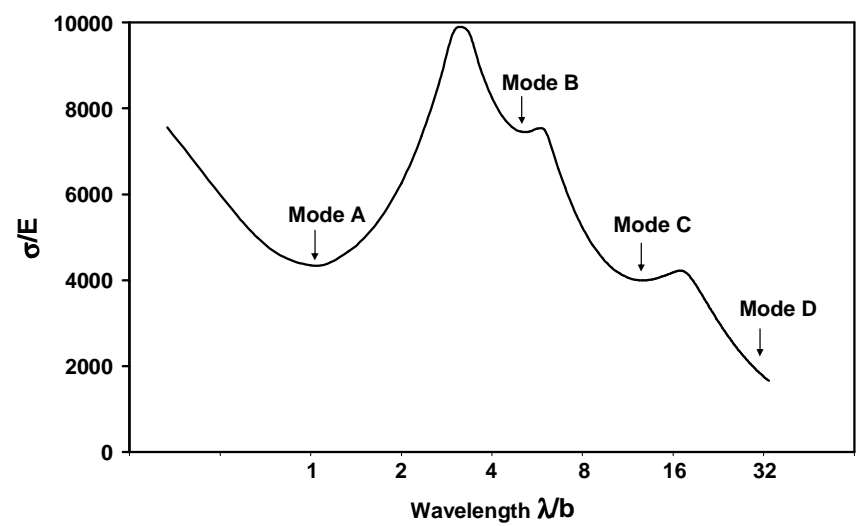

Figure 5. Normalized plots of buckling stress $\boldsymbol{\sigma}$ against half-wavelength $\boldsymbol{\lambda}$ for the panel of Fig. 4. The graph shows the first eigenvalue only and the buckling modes at four regions A, B, C, D are shown in Fig. 6. 


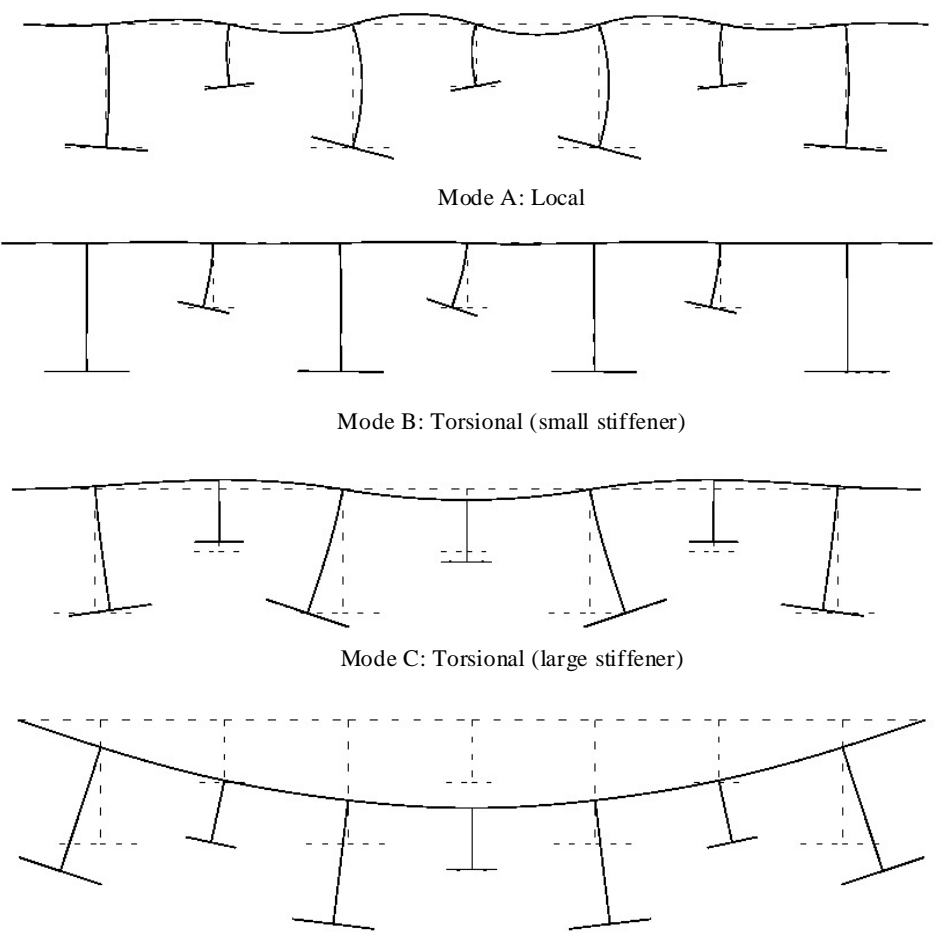

Mode D: Overall

Figure 6. The computed buckling modes for the four points A, B, C and D of Fig. 5. The unperturbed panel is shown in its original position in dashed lines. Note mode $\mathrm{C}$ can be considered overall buckling with respect to the small stiffener.

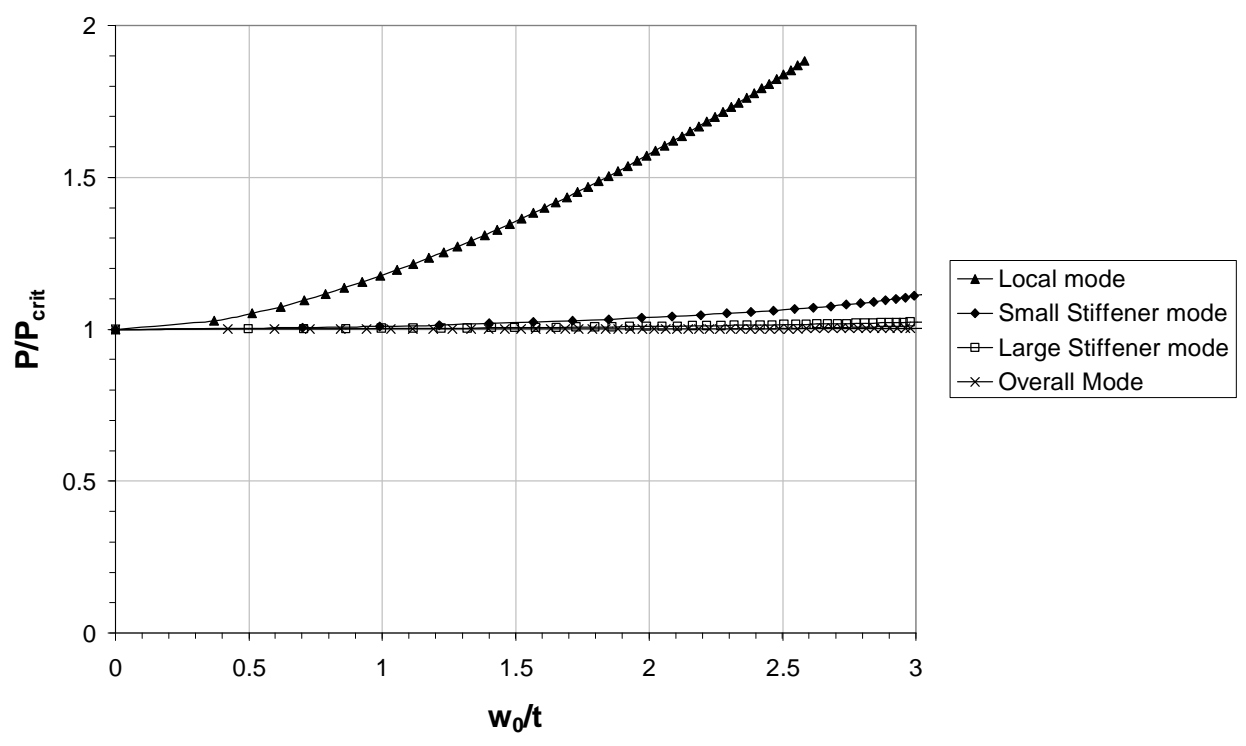

Figure 7. Normalized load versus out-of-plane deflection for each bucking mode type

American Institute of Aeronautics and Astronautics 
For overall modes the longitudinal line junctions between the web and the skin, and between the web and the flange, displace and therefore are not straight. As seen there is also one half wave across the width which looks similar to a half sine wave. Modes B and C show the small and large stiffeners, respectively, in a torsional mode. Here the line junction between the web and the skin does not displace but the line junction between the web and the flange does. Modes B and C are sometimes known as 'tripping' due to the appearance of the stiffeners. The difference between these two modes depends on the ability (i.e., the in-plane stiffness) of the flanges to keep the line junctions between the flanges and webs essentially straight.

\section{B. Postbuckling Behavior}

The postbuckling load versus out-of-plane displacement plot, obtained using VICONOPT, is shown in Fig. 7. The figure shows the postbuckling behavior for all four modes. No imperfection is assumed so that all plots have zero out-of-plane displacement at initial buckling. The local mode (Mode A) plot shows a growth in the out-of-plane deflection with load. Only the small stiffener mode (Mode B) shows evidence of stable postbuckling behavior. For the large stiffener mode and overall mode the load versus out-of-plane deflection plots are essentially horizontal showing no postbuckling stability for the deflection range shown. All plots are shown passing through the point $(0,1)$ but it should be noted that initial buckling for the different modes occurs at different loads.

The postbuckling stiffnesses of the component plates are not shown. This is because they show similar behavior to the results of the blade stiffened panel, i.e., the plates that precipitate buckling (and will therefore displace out-ofplane by a larger amount) have a larger loss of stiffness than neighboring plates. It should be noted here that for this panel the aspect ratio of the large stiffener webs is the same as the inter-stiffener portions of skin. This therefore is not an ideal panel for this investigation, as this characteristic has the effect of reducing the gradient of the load versus end shortening plot (for the local mode) due to a larger number of component plates with reduced stiffness. Only the component plates of the small stiffeners in Mode B initiated postbuckling behavior have a significant reduction in stiffness compared to the prebuckled state. The blades of the stiffened panel in Section 3 were very well selected in this regard as can be seen by an inspection of their aspect ratio.

\section{Conclusion}

The postbuckling solutions obtained by VICONOPT are not the result of a fully non-linear analysis, but of a bifurcation analysis of the panel in its assumed buckled state. The results show VICONOPT provides an accurate and inexpensive analysis of the initial postbuckling behavior of panels. Reasonable agreement has been obtained with results obtained using ABAQUS. To conduct postbuckling analysis of the panel it is possible using VICONOPT for any mode to be taken as critical, representing an advantage over finite element codes.

This study represents an initial investigation into the postbuckling stability of panels with a torsional mode and considered metal panels only with axial compression loading. Elastic behavior has been assumed throughout. The onset of plasticity would rapidly reduce any postbuckling stability that existed in the elastic range. The panel selected was not an optimized panel. Future work should include an optimized geometry along with mode jumping characteristics ${ }^{16}$ to accurately model the panel behavior.

An implication for panel designers is that mass can be saved if the initial buckling mode is small stiffener torsional buckling. The authors suggest that any mode jumping would be to a shorter half-wavelength mode and thus not catastrophic. For these panel geometries with small stiffener torsional buckling the geometry of the panel will dictate the quantity of postbuckling reserve.

\section{Acknowledgement}

The authors wish to thank the Engineering and Physical Sciences Research Council and Airbus U.K. for providing the financial assistance that made this work possible. In addition they would like to thank Mr. David Brindley for obtaining the NASTRAN results of Table 1.

\section{References}

${ }^{1}$ Hutchinson, J.W., and Koiter, W.T., "Postbuckling Theory”, Applied Mechanics Reviews, Vol. 23, 1970, pp. 1353-1366.

${ }^{2}$ Williams, F.W., "Stiffened panels with varying stiffener sizes", Journal of the Royal Aeronautical Society, Vol. 77, No. 751, July, 1973, pp 350-354.

${ }^{3}$ Butler, R., and Williams, F.W., "Optimum Design Using VICONOPT, a Buckling and Strength Constraint Program for Prismatic Assemblies of Anisotropic Plates”, Computers and Structures, Vol. 43, No. 4, 1992, pp. 699-708.

${ }^{4}$ Anderson, M.S., "Design of Panels Having Postbuckling Strength", Proceedings of 38th AIAA/ASME/ASCE/AHS/ASC Structures, Structural Dynamics, and Materials Conference, Kissimmee, Florida, 1997, pp. 2407-2413. 
${ }^{5}$ Watson, A., Featherston, C.A., and Kennedy, D., "Optimization of Postbuckled Stiffened Panels with Multiple Stiffener Sizes", Proceedings, Paper No. AIAA-2007-2207, 48th AIAA SDM Conference, Hawaii, USA, April 2007, pp 1-8, ISBN 156347-435-2.

${ }^{6}$ Lillico, M., Butler, R., Hunt, G.W., Watson, A., Kennedy, D., and Williams, F.W., "Analysis and Testing of a Post-Buckled Stiffened Panel", AIAA Journal, Vol. 40, No. 5, 2002, pp. 996-1000.

${ }^{7}$ Bushnell, D., and Rankin, C.C., "Optimum Design of Stiffened Panels with Substiffeners", Proceedings of 46th AIAA/ASME/ASCE/AHS/ASC Structures, Structural Dynamics, and Materials Conference, Austin, Texas, 2005, pp. 1587-1640.

${ }^{8}$ Bushnell, D., "PANDA2 - program for minimum weight design of stiffened, composite, locally buckled panels", Computers and Structures, Vol. 25, No. 4, 1987, pp. 469-605.

${ }^{9}$ MSC/NASTRAN, Software Package, Ver. 2005, MSC.Software Corp., Santa Ana, CA, 2005.

${ }^{10}$ Hibbitt, Karlsson, and Sorensen, Inc., ABAQUS/Standard User's Manual, Version 5.7, Pawtucket, RI, 1997.

${ }^{11}$ Wittrick, W.H., and Williams, F.W., "Buckling and Vibration of Anisotropic or Isotropic Plate Assemblies Under Combined Loadings”, International Journal of Mechanical Sciences, Vol. 16, No. 4, 1974, pp. 209-239.

${ }^{12}$ Wittrick, W.H., and Williams, F.W., "An Algorithm for Computing Critical Buckling Loads of Elastic Structures", Journal of Structural Mechanics, Vol. 1, No. 4, 1973. pp. 497-518.

${ }^{13}$ Anderson, M.S., and Kennedy, D., "Postbuckling of composite stiffened panels using exact strip analysis with Newton iteration", Proceedings of 49th AIAA/ASME/ASCE/AHS/ASC Structures, Structural Dynamics, and Materials Conference, Schaumburg, Illinois, 2008, Paper AIAA-2008-2184.

${ }^{14}$ Dawe, D.J. and Wang, S. "Postbuckling analysis of composite laminated panels", AIAA Journal, Vol. 38, No. 11, 2000 , pp. 2160-2170.

${ }^{15}$ Powell, S.M., Williams, F.W., Askar, A.-S., and Kennedy, D., "Local Postbuckling Analysis for Perfect and Imperfect Longitudinally Compressed Plates and Panels", Proceedings of 39th AIAA/ASME/ASCE/AHS/ASC Structures, Structural Dynamics, and Materials Conference, Long Beach, California, 1998, pp. 595-603.

${ }^{16}$ Watson, A., and Kennedy, D., "Mode Jumping in Post-buckled Stiffened Panels", Proceedings of 4th International Conference on Thin-walled Structures, Loughborough, UK, 2004, pp. 573-580. 